\title{
Development of safety performance index for intercity buses: an exploratory factor analysis approach
}

\begin{abstract}
In recent years in Malaysia, severe road crashes involving intercity buses have been increasing. With increased public concerns about intercity bus safety, effectively managing travel risk has become critical for both intercity bus operators and road safety policy makers. Intercity bus drivers are generally at a higher risk for crashes due to long hours of driving and exposure to different road conditions. Therefore, understanding and quantifying their risks and taking steps to manage them could improve intercity bus safety. The aim of this study is to establish a safety performance index for each risk domain to measure and compare intercity bus safety in terms of risk factors. The risk domains considered in this study were road environment conditions, bus driver driving behaviors and bus safety conditions. The weighted indicators were aggregated into the safety performance index for each risk domain was done using the Exploratory Factor Analysis method. The paired sample t-test was then applied to determine which safety performance indices were significantly different from each other. The results indicate that road environment conditions have contributed more to intercity bus safety risks on the east coast than on the west coast of peninsular Malaysia. The evidence presented in this study shows that different intercity bus companies showed mixed safety performance in different risk domains. Therefore, we suggest the development of targeted road safety programs for each intercity bus company to address intercity bus safety problems.
\end{abstract}

Keyword: Exploratory factor analysis; Intercity bus; Motor vehicle crashes; Safety performance index 